\title{
Metabolic profiling of ripe olive fruit in response to moderate water stress
}

\author{
F. Martinelli ${ }^{\mathrm{a}, \mathrm{b}, *}$, D. Remorini ${ }^{\mathrm{c}}$, S. Saia ${ }^{\mathrm{b}}$, R. Massai $^{\mathrm{c}}$, P. Tonutti $^{\mathrm{a}}$ \\ a Institute of Life Science, Scuola Superiore Sant'Anna, Piazza Martiri della Libertà 33, 56127 Pisa, Italy \\ ${ }^{\mathrm{b}}$ Department of Agricultural and Forest Science, University of Palermo, Viale delle Scienze, 90128 Palermo, Italy

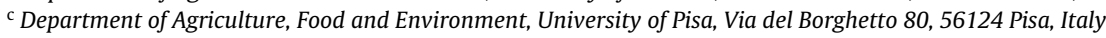

\section{A R T I C L E I N F O}

\section{Article history:}

Received 25 January 2013

Received in revised form 29 April 2013

Accepted 30 April 2013

\section{Keywords:}

Fruit metabolism

Metabolomics

Olea europaea

Ripe fruit

Water stress

\begin{abstract}
A B S T R A C T
The concentrations of different metabolites in olive (Olea europaea (L.)) fruit at harvest can be affected by water availability, with significant consequences on the composition and the quality of the resulting oil. The aim of the present study was to profile the metabolic composition of ripe olives (cv. Cipressino) grown under water-stress and irrigated conditions applied during the last part of the fruit developmental cycle (from pit hardening to commercial harvest). The imposed conditions resulted in a moderate water stress $(-3.5 \mathrm{MPa})$ at the end of the experimental period. Samples (pulp + skin) of fruit collected at the stage of complete epicarp pigmentation were analyzed by means of GC-MS. In total, 176 metabolites were detected, of which 57 were identified. Principal component analysis (PCA) of stress and non-stress treatments resulted in clearly separated profiles with the first principal component (PC1) mostly correlated with the organic acid content. Of the 57 compounds identified, 19 metabolites (organic acids, fatty acids, soluble sugars, and terpens) accumulated differently in the two sets of samples. A reduction in soluble sugars and unsaturated fatty acids was detected in water stressed samples, suggesting an acceleration of the ripening process. These results highlighted the validity of metabolic profiling to study the effects of water stress in terms of both fruit composition and physiology.
\end{abstract}

(c) 2013 Elsevier B.V. All rights reserved.

\section{Introduction}

In Mediterranean agro-ecosystems, water shortage is one of the main growth-limiting factors. Olive can survive under prolonged periods of drought through morphological, physiological and biochemical adaptation to a water deficit. Olive trees are able to take up water below the standard permanent wilting point measured for most crops (generally at $-1.5 \mathrm{MPa}$ ) and to recover from very low leaf water potential (-6.0 MPa) (Dichio et al., 2003). Water availability affects the general development and the composition of olive fruits inducing slight changes in the taste of the resulting oil (d'Andria et al., 2009; Gomez-Rico et al., 2009; Martinelli et al., 2012a,b). Particular attention has been given to the changes in nutraceuticals such as phenols, which are present as a complex mixture in both olive fruits and oil (Patumi et al., 2002; d'Andria et al., 2004; Gomez-Rico et al., 2007; Martinelli and

\footnotetext{
* Corresponding author at: Department of Agricultural and Forest Science, University of Palermo, Viale delle Scienze, 90128 Palermo, Italy. Tel.: +39 091 23862225; fax: +390917028153.

E-mail addresses: federico.martinelli@unipa.it (F. Martinelli), dremorini@agr.unipi.it (D. Remorini), sergio.saia@unipa.it (S. Saia), rmassai@agr.unipi.it (R. Massai), pietro.tonutti@sssup.it (P. Tonutti).
}

Tonutti, 2012) and characterized by antioxidant, anti-atherogenic, anti-cancerogenic properties (Hashim et al., 2008; Llorente-Cortes et al., 2010). Although the phenolic content in olives may differ by genotype, olive fruits harvested from irrigated trees in general show lower accumulation of total phenols (Tovar et al., 2001; Marsilio et al., 2006; Martinelli et al., 2012a,b). However, contrasting evidence means that the relation between water availability and the content of some particularly important polyphenols such as oleuropein has not yet been fully clarified (Patumi et al., 2002; Gomez-Rico et al., 2009). Besides phenol compounds, water availability also affects the concentration of some of the main metabolites in olive fruits such as free fatty acids, sterols and terpens (Berenguer et al., 2006; Gomez-Rico et al., 2007). However, other compounds still need to be studied and/or identified.

Transcriptomics has been widely applied to elucidate fruit metabolism changes in response to biotic and abiotic stresses (Martinelli et al., 2012a,b; Rivarola et al., 2011) or dehydration postharvest treatments (Rizzini et al., 2010). Metabolomics and metabolic profiling approaches are being applied in plant sciences as complementary techniques to validate data at a transcriptomic and proteomic level (Weckwerth, 2011; Fernie and Stitt, 2012). Metabolome analysis is extremely useful since metabolites influence the phenotype more directly than transcripts or proteins, given that they represent the final results of the different regulation 
levels existing in cells and tissues. Metabolic profiling and nontargeted metabolomic approaches have recently been exploited to understand metabolic changes and identify biomarkers in fruit, in relation to agronomic factors and biotic/abiotic stresses (Dandekar et al., 2010; Lee et al., 2012; Slisz et al., 2012; Tosetti et al., 2012).

The aim of this work was to evaluate the composition of ripe olive fruit through metabolic profiling in order to better characterize the effects of water stress during the final part of the fruit developmental cycle.

\section{Materials and methods}

\subsection{Plant material, experimental design, and fruit sampling}

Twelve 5-year-old olive (Olea europaea (L.), cv Cipressino) plants, grown in 171 pots with artificial substrates constituted by peat/pumice/sand $40 / 40 / 20(\mathrm{v} / \mathrm{v} / \mathrm{v})$ in Pisa, Italy, were selected based on similar canopy size and crop load. A complete randomized design with six replicates was established. Treatments were: water-stressed (WS) and irrigated (IR). The water stress conditions were created on six trees by wrapping the vase from day of the year (DOY) 216 (corresponding to pit-hardening stage) and until the ripe stage (DOY 236) when fruit samples were collected. The six IR trees were daily irrigated from DOY 216 to DOY 236 with $100 \%$ of effective evapotranspiration (IR). Effective evapotranspiration, determined by weighing each pot daily, was approximately $600-700 \mathrm{ml} \mathrm{d}^{-1}$. The diameters of 50 fruits per treatment were measured, with a digital calibre, every 5-10 days between DOY 196 and DOY 236. Data are reported as percentage variations compared to DOY 196. Two pools of 10 fruits were sampled from three trees per treatment at the ripe stage (complete pigmentation of the epicarp, DOY 236) and epicarp and mesocarp tissues were immediately frozen in liquid nitrogen and stored at $-80^{\circ} \mathrm{C}$.

\subsection{Stem water potentials and leaf gas exchange measurements}

$\mathrm{MD} \Psi_{\mathrm{S}}$ were measured using a Scholander type pressure chamber (Technogas, Pisa, Italy) on one leaf per tree with 6 replicates per treatment. The pressurization rate was $0.2 \mathrm{MPa}$ every $30 \mathrm{~s}$. Leaves, previously wrapped in aluminium foil and encased in polyethylene bags at least one hour before measurement, were cut off halfway along the stalk and immediately processed (Turner and Long, 1980). Gas exchanges at saturating light (namely at $>1200 \mu \mathrm{mol} \mathrm{m}^{-2} \mathrm{~s}^{-1}$ over the PAR waveband) were measured on medial leaves, using a portable infrared gas analyser Li-Cor 6400 (Li-Cor Inc., Lincoln, $\mathrm{NE}$, USA) operating at $35 \pm 0.5 \mathrm{~Pa}$ ambient $\mathrm{CO}_{2}$. Gas exchange was determined at $12.00 \mathrm{~h}$.

\subsection{Metabolite extraction and derivatization}

Two pools of 10 fruits per tree were analyzed for a total of 6 replicates for each treatment. Fruits were ground and $2 \mathrm{ml}$ of prechilled extraction solvent (MetOH: $\left.\mathrm{CHCl}_{3}: 1: 1\right)(\mathrm{v} / \mathrm{v}$ ) were added to $20 \mathrm{mg}$ of ground tissues (mesocarp and epicarp), stirred at $4{ }^{\circ} \mathrm{C}$ per $5 \mathrm{~min}$ and then centrifuged at $6000 \mathrm{rpm}$ for $2 \mathrm{~min}$. An aliquot of $20 \mu \mathrm{l}$ of supernatant was completely dried in a SpeedVac concentrator. Derivatization was performed with methoxyamine and $\mathrm{N}$-methy-N-(trimethylsilyl) trifluoroacetamide and separations were performed with an Agilent 6890 GC gas chromatographer (GC) coupled to a quadrupolar mass spectrometer (MS) and equipped with a Zorbax-C 8 column. Samples $(1 \mu \mathrm{l})$ were introduced in both splitless and split modes. In splitless conditions, a helium (carrier gas) purge flow of $10.5 \mathrm{ml} / \mathrm{min}$ was applied for $1 \mathrm{~min}$ (8.2 psi). In split mode, the split ratio was $1: 10$ and a split flow rate $10.3 \mathrm{ml} / \mathrm{min}$. The source temperature was $230^{\circ} \mathrm{C}$, oven was ramped by $10^{\circ} \mathrm{C} / \mathrm{min}$ from $60^{\circ} \mathrm{C}\left(1 \mathrm{~min}\right.$ initial time) to $325^{\circ} \mathrm{C}$ (10 min final time), resulting in a $37.5 \mathrm{~min}$ run time with cooling down to $60^{\circ} \mathrm{C}$. The carrier gas was flowed at a constant rate of $1 \mathrm{ml} / \mathrm{min}$. The MS was set at $150^{\circ} \mathrm{C}$, with a $5.90 \mathrm{~min}$ solvent delay time and scan range from 50 to 600 atomic mass units. Prior to the acquisition, the MS was autotuned using FC43 according to the instrument manual.

\subsection{Data acquisition and peak identification}

The relative concentrations were determined by peak areas. The Agilent Fiehn GC/MS Metabolomics RTL Library was used for metabolite identifications. This library contains searches for more than 700 common metabolites in relation to their GC/MS EI spectra and retention time indexes. All peak detections were manually checked for false positive and false negative assignments and corrected with retention time locking to reduce run-to-run retention time variation.

\subsection{Statistical analysis}

All the variables corresponding to proportion were arcsine transformed before analysis to better fit with the Gaussian law distribution. Data of fruit diameter, stem water potential and leaf gas-exchange were analyzed according to the experimental design using Statgraphics software. GC-MS data were analyzed using SAS software. A principal component analysis (PCA) was performed on the raw data (Princomp procedure, SAS Institute 2002) with the aim to discriminate between WS and IR treatments. Before carrying out the PCA, mean values per trait were standardized to a mean equal to 0 and standard deviation equal to 1 . Correlations among variables were calculated and where two or more variables were highly correlated $(r>0.70)$, one was discarded to avoid element weighting distortion as suggested by Pengelly and Maass (2001). The principal components that explained more than $10 \%$ total variance were retained for cluster analysis (CA; Cluster procedure, SAS Institute 2002), adopting the Euclidean distance as a measure of dissimilarity and the average method as a clustering algorithm. The number of clusters was estimated using pseudo $\mathrm{F}$ and $\mathrm{t} 2$ statistics (Milligan and Cooper, 1985).

\section{Results}

\subsection{Fruit growth, stem water potential and leaf gas-exchange data}

The different water regimes affected fruit diameter, stem water potential $\left(\mathrm{MD} \Psi_{\mathrm{S}}\right)$ and leaf gas exchange (net photosynthesis, $\mathrm{P}_{\mathrm{N}}$; stomatal conductance, $g_{S}$,) at the end of the experimental period (DOY 236). Compared to the first measurement (DOY 196), fruit diameter increase at harvest was 33\% and 28\% in IR and WS trees, respectively (Fig. $1 \mathrm{~A}$ ). $M D \Psi_{\mathrm{S}}$ (Fig. 1B) values remained constant in irrigated pots (around -2.0 MPa) throughout the whole experiment, whereas lack of irrigation led to a reduction in $M D \Psi_{S}$ (up to $-3.7 \mathrm{MPa}$ at DOY 236). These data indicate that a moderate water stress was applied.

At the end of experimental period $\mathrm{P}_{\mathrm{N}}$ and $\mathrm{g}_{\mathrm{S}}$ were $50 \%$ and $61 \%$ lower in WS than in IR olive trees, respectively (Fig. 2A and B). Fruit drop from DOY 196 to DOY 236 was not statistically different between treatments (around $4 \%$ in both cases).

\subsection{Metabolite profiling analysis}

The non-targeted metabolomic analysis displayed a total of 176 peaks, 57 of which were identified though a comparison with the Agilent Fiehn GC/MS Metabolomics RTL Library and mass spectra interpretation. The compounds identified were grouped as acids 

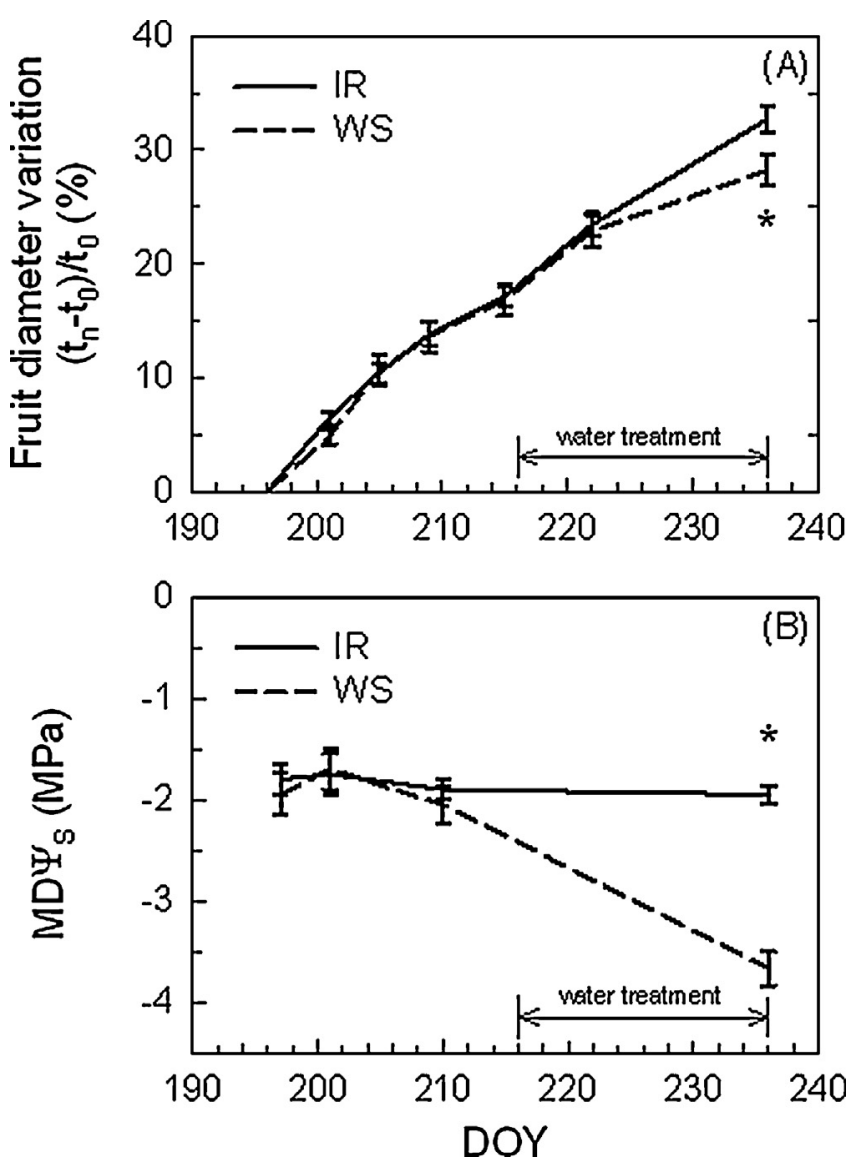

Fig. 1. (A) Fruit diameter variations (in \% referred to DOY 196) measured in irrigated (IR) and water stressed (WS) potted olive trees. Means ( \pm standard error) with asterisk are significantly different $(n=50, P \leq 0.05)$.(B) Midday stem water potential $\left(\mathrm{MD} \Psi_{\mathrm{S}},-\mathrm{MPa}\right.$ ) measured in irrigated (IR) and water-stressed (WS) potted olive trees. Means ( \pm standard error) with asterisk are significantly different $(n=5$, $P \leq 0.05)$.

(aromatic, non aromatic and fatty), sugars (soluble and structural) and terpens (Table 1). Considering these groups of metabolites, WS significantly reduced total sugars (TSs) and total soluble sugars (TSSs): since total acids (TAs) appeared not to be affected, WS resulted in a reduction in the TSS/TA ratio. No significant difference

Table 1

Average composition (as area, in arbitrary units, of the chromatographic peaks) of IR and WS fruit extracts.

\begin{tabular}{lrrl}
\hline Class of compounds & \multicolumn{1}{l}{ IR } & \multicolumn{1}{l}{ WS } & -value $^{\mathrm{a}}$ \\
\hline Total acids (TA) & 54.57 & 51.22 & 0.40 \\
Non-aromatic organic acids & 18.97 & 16.01 & 0.11 \\
Aromatic organic acids & 3.66 & 4.17 & 0.48 \\
Total fatty acids (FA) & 31.95 & 31.03 & 0.70 \\
$\quad$ SFA & 25.83 & 26.92 & 0.57 \\
UFA $^{\mathrm{b}}$ & 6.12 & 4.11 & $\mathbf{0 . 0 4}$ \\
Total sugars & 42.40 & 32.37 & $\mathbf{0 . 0 2}$ \\
Total soluble sugars (TSS) & 40.94 & 30.93 & $\mathbf{0 . 0 2}$ \\
Structural sugars & 1.45 & 1.44 & 0.88 \\
Terpens & 1.47 & 3.20 & $\mathbf{0 . 0 0 2}$ \\
TSS to TA ratio & & & $\mathbf{0 . 0 3}$ \\
TSS to FA ratio & 0.75 & 0.61 & $\mathbf{0 . 0 1}$ \\
SFA to UFA ratio & 1.81 & 1.58 & $\mathbf{0 . 0 3}$ \\
\hline
\end{tabular}

a $P$-values $\leq 0.05$ are shown in bold.

b Saturated fatty acids.

c Unsaturated fatty acids.
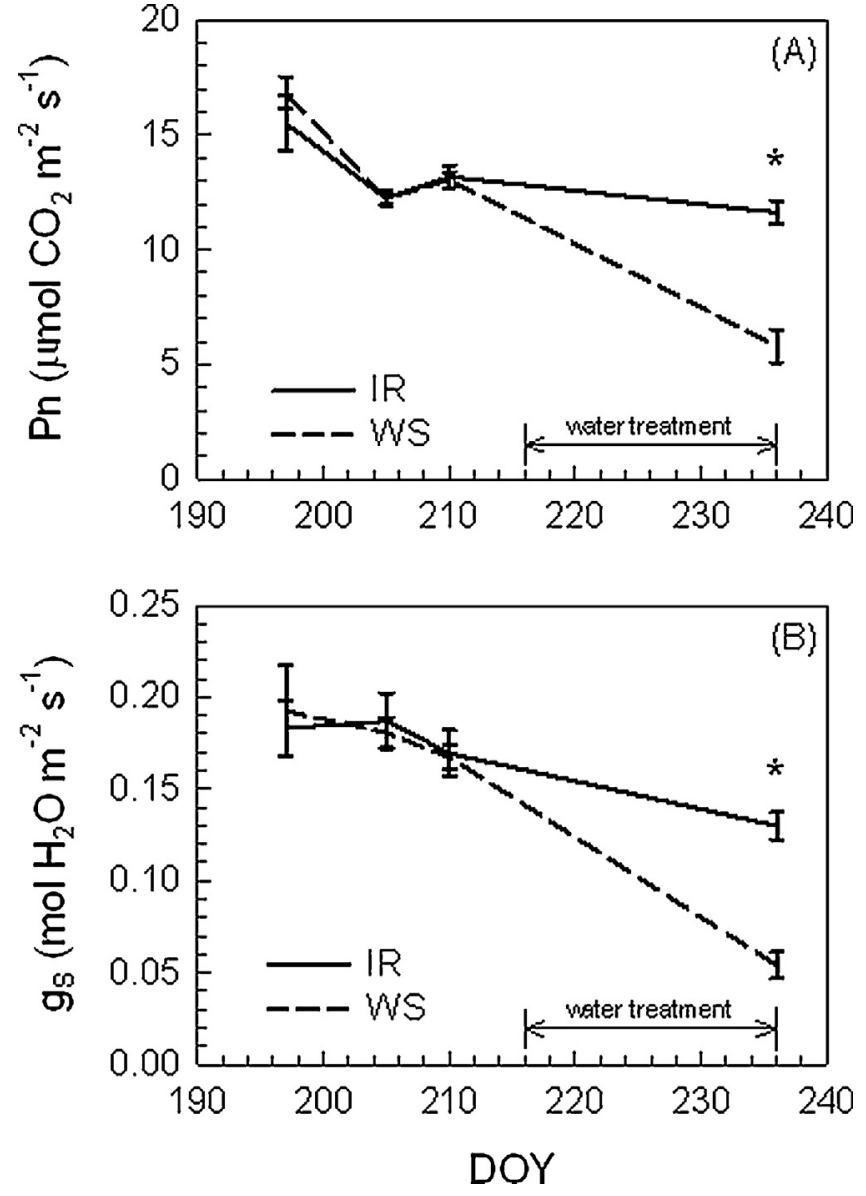

Fig. 2. Net photosynthesis $\left(\mathrm{P}_{\mathrm{N}}, \mu \mathrm{mol} \mathrm{CO} \mathrm{m}^{-2} \mathrm{~s}^{-1}\right.$; (A) and stomatal conductance ( $\mathrm{gs}_{\mathrm{s}}, \mathrm{mol} \mathrm{H}_{2} \mathrm{O} \mathrm{m}^{-2} \mathrm{~s}^{-1}$; (B) in irrigated (IR) and water-stressed (WS) potted olive trees. Means ( \pm standard error) with asterisk are significantly different $(n=9, P \leq 0.05)$.

was observed in terms of total (FA) and saturated fatty acid (SFA), whereas unsaturated fatty acids (UFA) decreased in the WS samples (Table 2), resulting in a change in the SFA/UFA ratio. Terpenes markedly increased in the WS samples.

The different water regimes caused significant $(P$ value $\leq 0.1)$ variations in 19 of the 57 compounds identified. The most pronounced and significant $(P \leq 0.001)$ changes occurred in terms of ascorbic acid, oleic acid, altrose, $\alpha$-glucopyransosyl fructose, and galactinol, which decreased in WS samples, and arachidic acid, which was more abundant when stress conditions were applied (Table 2). Although to a lesser extent, the amounts of other important metabolites were significantly affected by water stress $(0.001 \leq P \leq 0.05)$ : glucaric acid, dulcitol, inositol, lauric acid (less abundant than in the irrigated treatment) and 3-hydroxynthranilic acid, palmitic acid, lyxose, melezitose, erythrodiol, and loganin (higher abundance in WS samples). Slightly significant differences were also observed for pelargonic acid (less abundant in WS samples) and citric acid and arabitol (more abundant in WS samples) (Table 2).

PCA was performed using the data of 36 metabolites out of the 57 identified (21 compounds were excluded to avoid PCA disturbance due to the fact that they were highly correlated with the 36 selected metabolites). The two treatments were clearly separated in the PCA (Fig. 3). The first principal component (PC1) was mostly correlated with the organic acid content (Table 3), however, a low correlation was found between the content in the individual compounds identified and the principal components. 
Table 2

Metabolites (expressed as area, in arbitrary units, of chromatographic peaks) significantly $(P \leq 0.1)$ different in IR and WS fruit extracts.

\begin{tabular}{|c|c|c|c|c|c|}
\hline Class of compounds & Compounds & IR & WS & Variation [(WS/IR)-1] (\%) & $P$ value \\
\hline \multirow[t]{3}{*}{ Non-aromatic organic acids } & Ascorbic & 2.63 & 0.65 & -306.4 & $\leq 0.001$ \\
\hline & Citric & 1.86 & 3.14 & 40.9 & 0.08 \\
\hline & Glucaric & 4.40 & 2.68 & -64.1 & 0.004 \\
\hline Aromatic organic acids & 3-Hydroxyanthranilic & 0.99 & 2.00 & 50.5 & 0.01 \\
\hline \multirow[t]{4}{*}{ Saturated fatty acids } & Pelargonic C9:0 & 3.43 & 2.36 & -45.5 & 0.07 \\
\hline & Lauric C12:0 & 3.67 & 2.54 & -44.7 & 0.04 \\
\hline & Palmitic C16:0 & 1.92 & 3.08 & 37.7 & 0.002 \\
\hline & Arachidic C20:0 & 1.57 & 2.73 & 42.3 & $\leq 0.001$ \\
\hline Unsaturated fatty acids & Oleic C18:1 & 3.64 & 1.42 & -155.6 & $\leq 0.001$ \\
\hline \multirow[t]{8}{*}{ Soluble sugars } & $\alpha$-Glucopyranosyl fructose & 4.44 & 2.63 & -68.7 & $\leq 0.001$ \\
\hline & Altrose & 1.66 & 0.60 & -174.3 & $\leq 0.001$ \\
\hline & Arabitol & 0.84 & 1.65 & 48.9 & 0.09 \\
\hline & Dulcitol & 1.82 & 0.60 & -203.2 & 0.001 \\
\hline & Galactinol & 2.29 & 0.73 & -215.8 & $\leq 0.001$ \\
\hline & Inositol & 4.01 & 1.50 & -166.6 & 0.003 \\
\hline & Lyxose & 2.62 & 3.80 & 31.0 & 0.002 \\
\hline & Melezitose & 1.90 & 2.95 & 35.6 & 0.01 \\
\hline \multirow[t]{2}{*}{ Terpens } & Erythrodiol & 0.69 & 1.73 & 60.5 & 0.01 \\
\hline & Loganin & 0.78 & 1.47 & 46.6 & 0.001 \\
\hline
\end{tabular}

Table 3

Correlation coefficients between the first (PC1), second (PC2) and third (PC3) principal components and the 36 selected characters.

\begin{tabular}{|c|c|c|c|}
\hline & PC1 & PC2 & $\mathrm{PC} 3$ \\
\hline \multicolumn{4}{|l|}{ Organic acids } \\
\hline$\alpha$-ketoglutaric & -0.19 & -0.27 & 0.03 \\
\hline dehydroascorbic & -0.34 & 0.12 & 0.14 \\
\hline fumaric & -0.06 & 0.26 & -0.12 \\
\hline glucaric & -0.28 & 0.05 & 0.07 \\
\hline 3-hydroxyanthranilic & 0.28 & 0.00 & 0.00 \\
\hline lactic & 0.05 & 0.17 & -0.05 \\
\hline malic & -0.17 & -0.17 & -0.12 \\
\hline shikimic & -0.15 & -0.26 & -0.12 \\
\hline succinic & -0.08 & 0.04 & -0.07 \\
\hline trans aconitic & 0.20 & -0.27 & 0.13 \\
\hline \multicolumn{4}{|l|}{ Phenols } \\
\hline dihydroxyphenylglycol & 0.23 & 0.19 & -0.01 \\
\hline tyrosol & -0.01 & 0.22 & 0.14 \\
\hline \multicolumn{4}{|l|}{ Unsaturated fatty acids } \\
\hline palmitoleic & -0.02 & 0.05 & -0.32 \\
\hline \multicolumn{4}{|l|}{ Saturated fatty acids } \\
\hline behenic & 0.02 & 0.24 & -0.08 \\
\hline capric & -0.05 & 0.07 & -0.32 \\
\hline caprylic & 0.08 & -0.07 & 0.24 \\
\hline decanoic & 0.22 & 0.23 & 0.05 \\
\hline lauric & -0.27 & -0.08 & -0.02 \\
\hline lignoceric & 0.24 & 0.04 & 0.31 \\
\hline pelargonic & -0.16 & 0.09 & 0.23 \\
\hline stearic & 0.13 & -0.01 & 0.20 \\
\hline \multicolumn{4}{|l|}{ Sugars } \\
\hline allose & 0.14 & 0.16 & -0.17 \\
\hline arabitol & 0.09 & -0.26 & -0.07 \\
\hline fucose & 0.09 & 0.09 & 0.28 \\
\hline galactose & -0.06 & 0.17 & 0.17 \\
\hline glucose & -0.05 & -0.08 & 0.03 \\
\hline lyxose & 0.31 & -0.09 & -0.08 \\
\hline maltose & -0.08 & -0.03 & -0.29 \\
\hline mannitol & -0.20 & -0.12 & 0.25 \\
\hline melezitose & 0.22 & -0.07 & -0.29 \\
\hline palatinitol & 0.10 & -0.19 & 0.10 \\
\hline ribitol & -0.06 & 0.26 & 0.12 \\
\hline threitol & -0.15 & 0.19 & -0.10 \\
\hline xylitol & 0.09 & -0.15 & -0.05 \\
\hline \multicolumn{4}{|l|}{ Others } \\
\hline glycerol-1-Pi & 0.11 & -0.26 & 0.07 \\
\hline synephrine & -0.12 & -0.17 & 0.08 \\
\hline
\end{tabular}

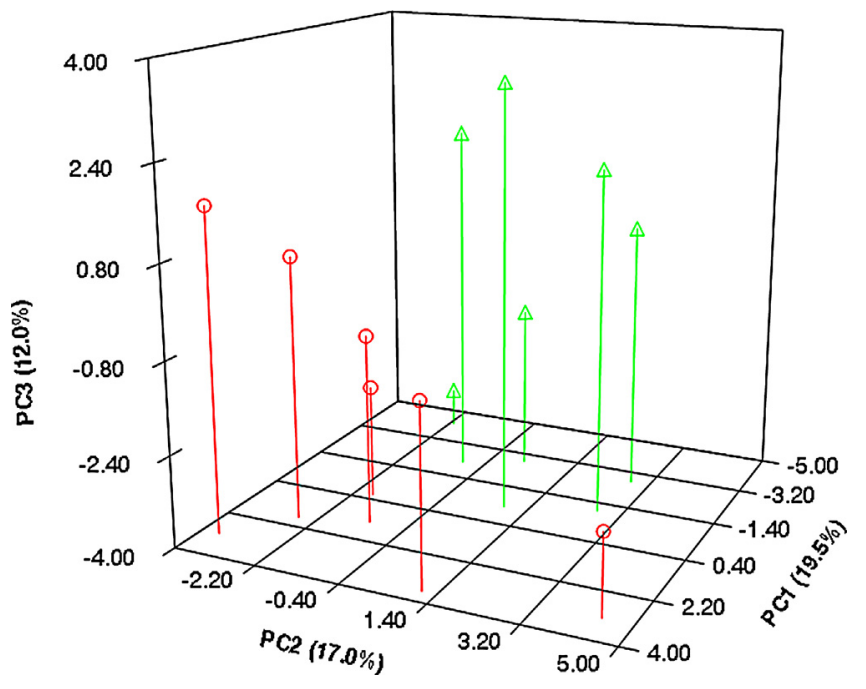

Fig. 3. 3D scatter plot for $P C 1$ vs $P C 2$ vs $P C 3$ for raw data from irrigated (green triangles) and water-stressed (red circes) samples. The percentage of total variance explained from each principal component is shown in parentheses. Axes are in eigenvalues scales. (For interpretation of the references to colour in this figure legend, the reader is referred to the web version of the article.)

\section{Discussion}

Olive oil is well known as a source of fats and nutraceuticals. In Mediterranean countries, it is preferred to other vegetal oils such as linseed and soy oils due to its better composition in fatty acids and the presence of high concentrations of antioxidants (namely polyphenols and tocopherols). The composition of the olive fruit at harvest is affected by various environmental and agronomic factors, including water availability throughout the growth cycle, and particularly in the final stages of development. Although much is known about the effects of water stress on the concentration of compounds important in terms of olive and oil quality (Patumi et al., 2002; d'Andria et al., 2009; Gomez-Rico et al., 2009), new analytical approaches are useful to further characterize the responses to this stress and to identify new metabolites that show different accumulations in ripe olives.

The conditions applied in our studies corresponded to a moderate water stress as demonstrated by MD $\Psi$ s and leaf gas exchange 
data, which have been shown to be reliable parameters for monitoring water relations in potted (Pavel and Fereres, 1998), young (Moriana and Fereres, 2002) and mature (Fernandez et al., 2006) olive trees. Although the water stress conditions were mild, final fruit growth was affected and significant changes in the metabolome were detected. Samples from WS treatment were clearly separated from those of IR treatment by the PC1 in the PCA, whereas few relations were observed between the PCs 2 and 3 and water availability. PC1 was mainly influenced by the content in organic acids, which are minor components of the olive fruit, approximately $1.5 \%$ of the fleshy part. Organic acids play an important role in metabolic activity because of their involvement in both the oxidative and synthetic pathways of carbohydrates (Cunha et al., 2001) and fatty acids. In addition, they increase the osmotic potential of the cell, which implies an increased water holding capacity. Glucaric and, especially, ascorbic acids were less abundant in WS drupes, and vice versa for citric acid. Ascorbic acid is a naturally-occurring organic compound with antioxidant properties (Stefanelli et al., 2010). Few studies on the effects of water deficiency on ascorbic acid content in fruit are available: in tomato, both increases (Dumas et al., 2003) and decreases (Rudich et al., 1977) have been found. The marked decrease in ascorbic acid observed in the WS samples (the most pronounced percentage variation considering the whole set of 19 compounds) must be highlighted considering the importance of vitamin $C$ in human nutrition. Glucaric acid is found in many fruits and vegetables, with the highest concentrations in grapefruits, apples, oranges, and cruciferous vegetables. Indeed, the lower amount of glucaric acid in olive fruit under water deficiency needs to be further investigated since it may reduce important qualitative aspects of the oil (Walaszek, 1990; Zóltaszek et al., 2008).

A marked increase in palmitic and arachidic acids and a slight reduction in pelargonic and lauric acids was observed in the WS treatment compared with the IR treatment. The low amount of saturated fatty chains, affected by cultivars and particular pedoclimatic conditions, is an important quality marker. Saturated fatty acids are generally considered to be "bad" fats since they increase the synthesis of cholesterol and promote cardiovascular problems (Mannina et al., 2010). Palmitic acid is a major component of palm oil and is generally associated with increased risks of developing cardiovascular diseases. Arachidic acid is another undesirable saturated fatty acid, which is a minor constituent of peanut oil $(1.1 \%-1.7 \%)$ and corn oil (3\%). Differences in these two saturated fatty acids might also affect the organoleptic characteristics of the produced oil. Indeed, an oil with a high content of saturated fatty acids is more viscous and persistent in the mucous of the oral cavity ("fatty sensation"). A decrease in the unsaturated fatty acid content (Table 1), especially of oleic acid (Table 2), was observed in WS. These results partially agree with previous studies that have shown the effect of irrigation on the levels of saturated (stearic and behenic) and unsaturated (oleic, linoleic, and eicosenoic) acids (Tognetti et al., 2007). However, other studies did not report variations in acidic composition in response to different water regimes (Motilva et al., 2000). The saturated/unsaturated ratio was higher in WS olives, which is an important observation in terms of the quality parameters of the oil given that this trait is related to the stability of the oil against oxidative damage (Rotondi et al., 2004). It is possible that under WS, olives are subjected to oxidative stress, which may alter the synthesis of unsaturated fatty acids or increase their degradation.

Polyols (sugar alcohols) are the reduced form of aldose and ketose sugars. Numerous roles have been attributed to polyols, such as the translocation and storage of photosynthates (Kanayama, 2009). Polyols are osmotically active solutes accumulated in response to abiotic stress (i.e. myo-inositol, arabitol) to compensate for reduced cell water potential (Popp and Smirnoff, 1995).
There is a growing interest in studying the metabolism of soluble sugar compounds including alditols (myo-inositol, mannitol, sorbitol, dulcitol, galactinol, etc.). Olive trees are particularly resistant to water deficiency and a wide range of polyol compounds, such as mannitol and myo-inositol, seem to be involved in the basic mechanisms of resistance to adverse environmental conditions (Cataldi et al., 2000). Their hydroxyl groups may be able to establish hydrogen bonds in the case of limited water availability, thus protecting enzymes and membranes (Noiraud et al., 2001). Various studies have reported an increase in polyol content in response to abiotic stresses such as drought or salinity in plants (Press, 1995; Loescher and Everard, 1996). Since polyol synthesis occurs in mature leaves, an increase in abundance in sink organs is related to an increased transport of polyols. In our study, TSS content was lower in WS compared with the IR treatment. Other studies (Sofo et al., 2007) have shown that stomatal closure starts at $-2.5 \mathrm{MPa}$. In the present study, MD $\Psi_{\mathrm{S}}$ was 1.5 fold lower than this threshold, which may be due to the lower photosynthetic activity in WS than IR treatment, which itself may be responsible for the lower sugar content. In addition, Cherubini et al. (2009) and Migliorini et al. (2011) reported that sugar concentration decreases throughout olive fruit ripening following a sygmoidal model. The lower TTS content detected in WS samples supports the hypothesis of an acceleration of the ripening syndrome in olive fruit subjected to moderate water stress applied in the final stages of fruit development. In Martinelli et al. (2012a) we reported that, based on a metabolic profiling analysis and the accumulation of primary and secondary metabolites in fruit, irrigation delays ripening.

Besides fatty acids, polyols and organic acids, erythrodiol and loganin were identified as being affected by water stress. Although present in olive oil as minor components, terpenes are volatile compounds and contribute to the sensory quality of olive oil. Their amount is highly affected by the growing environment of the trees (Mannina et al., 2001). For example, olive oils from Liguria in Italy are always characterized by a high amount of terpenes, which is considered as a "sensory marker" specific to these olive oils (Mannina et al., 2010). Water deficits affect the transcript accumulation and pathways associated with the production of volatile compounds, as reported by Deluc et al. (2009) in grape berries. O. europaea (L.) has long been known to contain a variety of triterpenoids including erythrodiol, oleanolic acid, and maslinic acid. Non-steroidal triterpenes are metabolized into more-oxygenated compounds, which serve as substrates for the synthesis of triterpenic saponins. From a health perspective, these compounds contribute to the cancer protective activity of the Mediterranean diet (Connolly and Hill, 2005). Interestingly a significant increase in erythrodiol and loganin was observed in WS olives. These data are in agreement with another study on the effects of different water regimes on olive quality (Berenguer et al. 2006) and are of particular interest due to the health-related properties of these compounds. Erythrodiol is the intermediate from which oleanolic acid and its isomer maslinic acid are formed (Stiti et al., 2007). The concentration of this pentacyclic triterpenic alcohol in olive oil is around $90 \mathrm{mg} / \mathrm{kg}$ (Blanch et al., 1998). It has been described as having anti-inflammatory activities (De la Puerta et al., 2000), vasorelaxant effects on rat aorta (Rodriguez-Rodriguez et al., 2004) and antioxidant properties (Perona et al., 2005). In addition, the modulation of cytokine secretion by erythrodiol in human mononuclear cells, antiproliferative and apoptotic activity in HT29 human adenocarcinoma cells have been recently described (Marquez-Martin et al., 2006).

Loganin is an iridoid glycoside found in the Flos lonicerae, Fruit cornus, and Strychonos nux vomica. Loganin has important health properties since it regulates the immune system and has antiinflammatory and anti-shock effects (Frederich et al., 2004). The increased accumulation of terpenes in WS ripe olives could be the 
result of an increase in their synthesis. In Martinelli et al. (2012a,b) we reported that a decrease in $\beta$-amyrin synthase gene expression, responsible for the cyclization of squalene in $\beta$-amyrin (triterpenoid pathway), was observed in olive fruit grown under irrigated conditions.

In conclusion, we believe our study confirms metabolic profiling is a valid means to study the effects of stress applied to fruit crops, and in particular in olive fruits. In fact we managed to discriminate and evaluate the effect of moderate water stress in the composition of ripe olives and highlighted that sugars and terpenes represent metabolic categories that are highly affected by different levels of water availability during the final stages of fruit development. A combination of such metabolic profiling and/or untargeted metabolomics with transcript analyses will represent a next step for a better elucidation of basic responses of olives to different water conditions.

\section{Acknowledgements}

This work was financially supported by Fondazione Cassa di Risparmio di Lucca and Progetto Strategico MiPAAF OLEA-“Genomica e Miglioramento Genetico dell'Olivo" (D.M. 27011/7643/10) funded by Italian Ministry of Agriculture. We would like to thank Prof. Oliver Fiehn, Dr. Mine Palazoglu, Dr. Dinesh Kumar Barupal of the Metabolomics Fiehn Lab (Genome Center, University of California, Davis) for their kind collaboration in the metabolic profiling analysis.

\section{References}

Berenguer, M.J., Vossen, P.M., Grattan, S.R., Connell, J.H., Polito, V.S., 2006. Tree irrigation levels for optimum chemical and sensory properties of olive oil. HortScience 41, 42-432.

Blanch, G.P., Villen, J., Herraiz, M., 1998. Rapid analysis of free erythrodiol and uvaol in olive oils by coupled reversed phase liquid chromatography gas chromatography. J. Agric. Food Chem. 46, 1027-1030.

Cataldi, T.R.I., Margiotta, G., Iasi, L., Dichio, B., Xiloyannis, C., Bufo, S.A., 2000. Determination of sugar compounds in olive plant extracts by anionexchange chromatography with pulsed amperometric detection. Anal. Chem. 72, 3902-3907.

Cherubini, C., Migliorini, M., Mugelli, M., Viti, P., Berti, A., Cini, E., Zanoni, B., 2009. Towards a technological ripening index for olive oil fruits. J. Sci. Food Agric. 89, $671-682$.

Connolly, J.D., Hill, R.A., 2005. Triterpenoids. Nat. Prod. Rep. 22, 230-248.

Cunha, S.C., Ferreira, I.M.P.L.V.O., Fernandes, J.O., Faria, M.A., Beatriz, M., Oliveira, P.P., Ferreira, M.A., 2001. Determination of lactic, acetic, succinic and citric acids in table olives by HPLC/UV. J. Liq. Chromatogr. Relat. Technol. 24, 1029-1038.

Dandekar, A.M., Martinelli, F., Davis, C.E., Bhushan, A., Zhao, W., Fiehn, O., Skogerson, K., Wohlgemuth, G., D'Souza, R., Roy, S., Reagan, R.L., Lin, D., Cary, R.B., Pardington, P., Gupta, G., 2010. Analysis of early host responses for asymptomatic disease detection and management of specialty crops. Crit. Rev. Immunol. 30, 277-289.

d'Andria, R., Lavini, A., Morelli, G., Patumi, M., Terenziani, S., Calandrelli, D., Fragnito, F., 2004. Effects of water regimes on five pickling and double aptitude olive cultivars (Olea europaea (L.). J. Hortic. Sci. Biotechnol. 79, 18-25.

d'Andria, R., Lavini, A., Morelli, G., Sebastiani, L., Tognetti, R., 2009. Physiological and productive responses of Olea europaea L. cultivars Frantoio and Leccino to a regulated deficit irrigation regime. Plant Biosyst. 143, 222-231.

De la Puerta, R., Martinez-Dominguez, E., Ruiz-Gutierrez, V., 2000. Effect of minor components of virgin olive oil on topical anti-inflammatory assays. Z. Naturforsch. 55, 814-819.

Deluc, L.G., Quilici, D.R., Decendit, A., Grimplet, J., Wheatley, M.D., Schlauch, K.A., Merillon, J.M., Cushman, J.C., Cramer, G.R., 2009. Water deficit alters differentially metabolic pathways affecting important flavor and quality traits in grape berries of Cabernet Sauvignon and Chardonnay. BMC Genomics 10, 212-245.

Dichio, B., Xiloyannis Angelopoulos, K., Nuzzo, V., Bufo, S.A., Celano, G., 2003. Drought-induced variations of water relations parameters in Olea europaea. Plant Soil 257, 381-389.

Dumas, Y., Dadomo, M., Di Lucca, G., Grolier, P., 2003. Effects of environmental factors and agricultural techniques on antioxidant content of tomatoes. J. Sci. Food Agric. 83, 369-382.

Fernandez, J.E., Diaz-Espejo, A., Infante, J.M., Duran, P., Palomo, M.J., Chamorro, V., Giron, I.F., Villagarcia, L., 2006. Water relations and gas exchange in olive trees under regulated deficit irrigation and partial rootzone drying. Plant Soil 284, 273-291
Fernie, A., Stitt, M., 2012. On the discordance of metabolomics with proteomics and transcriptomics: coping with increasing complexity in logic, chemistry, and network interactions. Plant Physiol. 158, 1139-1145.

Frederich, M., Choi, Y.H., Angenot, L., Harnischfeger, G., Lefeber, A.W.M., Verpoorte, R., 2004. Metabolomic analysis of Strychnos nux-vomica, Strychnos icaja and Strychnos ignatii extracts by $\mathrm{H}-1$ nuclear magnetic resonance spectrometry and multivariate analysis techniques. Phytochemistry 65, 1993-2001.

Gomez-Rico, A., Salvador, M.D., Fregapane, G., 2009. Virgin olive oil and olive fruit minor constituents as affected by irrigation management based on SWP and TDF as compared to ETc in medium-density young olive orchards (Olea europaea L cv. Cornicabra and Morisca). Food Res. Int. 42, 1067-1076.

Gomez-Rico, A., Moriana, Salvador M.D., Perez, A., Olmedilla, D., Ribas, N., Fregapane, F.G., 2007. Influence of different irrigation strategies in a traditional Cornicabra cv. olive orchard of virgin olive oil composition and quality. Food Chem. 100, 568-578.

Hashim, Y., Rowland, I.R., McGlynn, H., Servili, M., Selvaggini, R., Taticchi, A., Esposto, S., Montedoro, G., Kaisalo, L., Wahala, K., Gill, C.I.R., 2008. Inhibitory effects of olive oil phenolics on invasion in human colon adenocarcinoma cells in vitro. Int. J. Cancer 122, 495-500.

Kanayama, Y., 2009. Physiological roles of polyols in horticultural crops. J. Jpn. Soc. Hortic. Sci. 78, 158-168.

Lee, J., Rudell, D.R., Davies, P.J., Watkins, C.B., 2012. Metabolic changes in 1-methylcyclopropene (1-MCP)-treated empire apple fruit during storage. Metabolomics 8, 742-753.

Llorente-Cortes, V., Estruch, R., Mena, M.P., Ros, E. Gonzalez, M.A.M., Fito, M. Lamuela-Raventos, R.M., Badimon, L., 2010. Effect of Mediterranean diet on the expression of pro-atherogenic genes in a population at high cardiovascular risk. Atherosclerosis 208, 442-450.

Loescher, W.H., Everard, J.D., 1996. Sugar alcohol metabolism in sinks and sources. In: Zamski, E., Schaffer, A.A. (Eds.), Photoassimilate Distribution in Plants and Crops,. CRC Press, New York, pp. 185-207.

Mannina, L., Patumi, M., Proietti, N., Bassi, D., Segre, A.L., 2001. Geographical characterization of Italian extra virgin olive oils using high-field H-1 NMR spectroscopy. J. Agric. Food Chem. 49, 2687-2696.

Mannina, L., Marini, F., Gobbino, M., Sobolev, A.P., Capitani, D., 2010. NMR and chemometrics in tracing European olive oils: the case study of Ligurian samples. Talanta 80, 2141-2148.

Marquez-Martin, A., De la Puerta, R., Fernandez-Arche, A., Ruiz-Gutierrez, V., Yaqoob, P., 2006. Modulation of cytokine secretion by pentacyclic triterpenes from olive pomace oil in human mononuclear cells. Cytokine 36, 211-217.

Marsilio, V., d’Andria, R., Lanza, B., Russi, F., Iannucci, E., Lavini, A., Morelli, G., 2006 Effect of irrigation and lactic acid bacteria inoculants on the phenolic fraction, fermentation and sensory characteristics of olive (Olea europaea L. cv Ascolana tenera) fruits. J. Sci. Food Agric. 86, 1005-1013.

Martinelli, F., Basile, B., Morelli, G., d'Andria, R., Tonutti, P., 2012a. Effects of irrigation on fruit ripening behavior and metabolic changes in olive. Sci. Hortic. 144 201-207.

Martinelli, F., Uratsu, S.L., Albrecht, U., Reagan, R.L., Phu, M.L., Britton, M., Buffalo, V., Fass, J., Leicht, E., Zhao, W., Lin, D., D’Souza, R., Davis, C.E., Bowman, K.D. Dandekar, A.M., 2012b. Transcriptome profiling of citrus fruit response to huanglongbing disease. Plos One 7, e38039.

Martinelli, F., Tonutti, P., 2012. Flavonoid metabolism and gene expression in developing olive (Olea europaea L.) fruit. Plant Biosyst. 146 (S1), 164-170.

Migliorini, M., Cherubini, C., Mugelli, M., Gianni, G., Trapani, S., Zanoni, B., 2011. Relationship between the oil and sugar content in olive oil fruits from Moraiolo and Leccino cultivars during ripening. Sci. Hortic. 129, 919-921.

Milligan, G.J., Cooper, M.C., 1985. An examination of procedures for determining the number of clusters in a data set. Psychometrika 50, 159-179.

Moriana, A., Fereres, E., 2002. Plant indicators for scheduling irrigation of young olive trees. Irrigation Sci. 21, 83-90.

Motilva, M.J., Tovar, M.J., Romero, M.P., Alegre, S., Girona, J., 2000. Influence of regulated deficit irrigation strategies applied to olive trees (Arbequina cultivar) on oil yield and oil composition during the fruit ripening period. J. Sci. Food Agric. 80, 2037-2043.

Noiraud, N., Maurousset, L., Lemoine, R., 2001. Transport of polyols in higher plants. Plant Physiol. Biochem. 39, 717-728.

Patumi, M., d'Andria, R., Marsilio, V., Fontanazza, G., Morelli, G., Lanza, B., 2002. Olive and olive oil quality after intensive monocone olive growing (Olea europaea L., cv. Kalamata) in different irrigation regimes. Food Chem. 77, 27-34.

Pavel, E.W., Fereres, E., 1998. Low soil temperatures induce water deficits in olive (Olea europea) trees. Physiol. Plant. 104, 525-532.

Pengelly, B.C., Maass, B.L., 2001. Lablab purpureus (L.) sweet - diversity potential use and determination of a core collection of this multi-purpose tropical legume. Genet. Resour. Crop Evol. 48, 261-272.

Perona, J.S., Arcemis, C., Ruiz-Gutierrez, V., Català, A., 2005. Effect of dietary higholeic-acid oils that are rich in antioxidants on microsomal lipid peroxidation in rats. J. Agric. Food Chem. 53, 730-735.

Popp, M., Smirnoff, N., 1995. Polyol accumulation and metabolism during waterstress. In: Smirnoff, N. (Ed.), Environment and Plant Metabolism. Flexibility and Acclimatation. Bioscientific Publishers Ltd, Oxford, pp. 199-215.

Press, M.C., 1995. Carbon and nitrogen relations. In: Press, M.C., Graves, J.D. (Eds.) Parasitic Plants. Chapman \& Hall, London, pp. 103-123.

Rivarola, M., Chan, A.P., Liebke, D.E., Melake-Berhan, A., Quan, H., Cheung, F. Ouyang, S., Folta, K.M., Slovin, J.P., Rabinowicz, P.D., 2011. Abiotic stress-related expressed sequence tags from the diploid strawberry Fragaria vesca f. semperflorens. Plant Genome 4, 12-23. 
Rizzini, F.M., Bonghi, C., Chkaiban, L., Martinelli, F., Tonutti, P., 2010. Effects of postharvest partial dehydration and prolonged treatments with ethylene on transcript profiling in skins of wine grape berries (Conference Paper). Acta Hortic. 877, 1099-1104.

Rodriguez-Rodriguez, R., Herrera, M.D., Perona, J.S., Ruíz-Gutierrez, V., 2004. Potential vasorelaxant effects of oleanolic acid and erythrodiol two triterpenoids contained in orujo olive oil, on rat aorta. Br. J. Nutr. 92, 635-642.

Rotondi, A., Bendini, A., Cerratani, L., Mari, M., Lecker, G., Toschi, T.G., 2004. Effect of olive ripening degree on the oxidative stability and organoleptic proprieties of $\mathrm{CV}$ Nostrana di Brisighella extra virgin olive oil. J. Agric. Food Chem. 52, 3649-3654.

Rudich, J., Kalmar, D., Geizenberg, C., Harel, S., 1977. Low water tensions in defined growth stages of processed tomato plants and their effects on yield and quality. J. Hortic. Sci. 52, 391-399.

Slisz, A.M., Breksa, A.P. III, Mishchuk, D.O., McCollum, G., Slupsky, C.M., 2012. Metabolomic analysis of Citrus infection by Candidatus liberibacter reveals insight into pathogenicity. J. Proteome Res. 11, 4223-4230.

Sofo, A., Manfreda, S., Dichio, B., Fiorentino, M., Xiloyannis, C., 2007. The olive tree: a paradigm for drought tolerance in Mediterranean climates. Hydrol. Earth Syst. Sci. Discuss. 4, 2811-2835.

Stefanelli, D., Goodwin, I., Jones, R., 2010. Minimal nitrogen and water use in horticulture: effects on quality and content of selected nutrients. Food Res. Int. 43, 1833-1843.
Stiti, N., Triki, T.S., Hartmann, M.A., 2007. Formation of triterpenoids throughout Olea europaea fruit ontogeny. Lipids 42, 55-67.

Tognetti, R., d'Andria, R., Sacchi, R., Lavini, A., Morelli, G., Alvino, A., 2007. Deficit irrigation affects seasonal changes in leaf physiology and oil quality of Olea europaea (cultivars Frantoio and Leccino). Ann. Appl. Biol. 150, 169-186.

Tosetti, R., Martinelli, F., Tonutti, P., Barupal, D.K., 2012. Metabolomics approach to studying minimally processed peach (Prunus persica) fruit. Acta Hortic. 934 1017-1022.

Tovar, M.J., Motilva, M.J., Romero, M.P., 2001. Changes in the phenolic composition of virgin olive oil from young trees (Olea europaea L cv. Arbequina) grown under linear irrigation strategies. J. Agric. Food Chem. 49, 5502-5508.

Turner, N.C., Long, M.J., 1980. Errors arising from rapid water loss in the measurement of leaf water potential by the pressure chamber technique. Aust. J. Plant Physiol. 7, 527-537.

Walaszek, Z., 1990. Potential use of D-glucaric acid-derivatives in cancer prevention Cancer Lett. 54, 1-8.

Weckwerth, W., 2011. Green systems biology - from single genomes, proteomes and metabolomes to ecosystems research and biotechnology. J. Proteomics 75, 284-305.

Zóltaszek, R., Hanausek, M., Kilianska, Z.M., Walaszek, Z., 2008. The biological role of D-glucaric acid and its derivatives: potential use in medicine. Postepy Hig. Med. Dosw. 62, 451-462. 